University of New Hampshire

University of New Hampshire Scholars' Repository

$9-2008$

\title{
Relation of modifiable neighborhood attributes to walking
}

\author{
Daniel A. Rodriguez \\ University of North Carolina at Chapel Hill \\ Semra Aytur \\ University of New Hampshire \\ Ann Forsyth \\ Cornell University \\ J Michael Oakes \\ University of Minnesota - Duluth \\ Kelly J. Clifton \\ University of Maryland - College Park
}

Follow this and additional works at: https://scholars.unh.edu/hmp_facpub

\section{Recommended Citation}

Daniel A. Rodríguez, Semra Aytur, Ann Forsyth, J. Michael Oakes, Kelly J. Clifton, Relation of modifiable neighborhood attributes to walking, Preventive Medicine, Volume 47, Issue 3, September 2008, Pages 260-264, ISSN 0091-7435, http://dx.doi.org/10.1016/j.ypmed.2008.02.028.

(http://www.sciencedirect.com/science/article/pii/S0091743508001163)

This Article is brought to you for free and open access by the Health Management and Policy at University of New Hampshire Scholars' Repository. It has been accepted for inclusion in Health Management and Policy Scholarship by an authorized administrator of University of New Hampshire Scholars' Repository. For more information, please contact Scholarly.Communication@unh.edu. 


\title{
Relation of modifiable neighborhood attributes to walking
}

\author{
Daniel A. Rodríguez *, Semra Aytur, Ann Forsyth, J. Michael Oakes, Kelly J. Clifton
}

Department of City and Regional Planning, University of North Carolina, Chapel Hill, CB 3140, Room 319, NC 27599-3140, USA

Department of Epidemiology, University of North Carolina, Chapel Hill, NC, USA

Department of City and Regional Planning, Cornell University, USA

Division of Epidemiology and Community Health, University of Minnesota, USA

Urban Studies and Planning Program, University of Maryland, USA

\section{A R T I C L E I N F O}

\section{Article history:}

Available online 10 March 2008

\section{Keywords:}

Built environment

Parking

Physical activity

Physical activity and public health

Walking

Transportation

Urban Planning

\section{A B S T R A C T}

Background. There is a paucity of research examining associations between walking and environmental attributes that are more modifiable in the short term, such as car parking availability, access to transit, neighborhood traffic, walkways and trails, and sidewalks.

Methods. Adults were recruited between April 2004 and September 2006 in the Minneapolis-St Paul metropolitan area and in Montgomery County, Maryland using similar research designs in the two locations. Self-reported and objective environmental measures were calculated for participants' neighborhoods. Selfreported physical activity was collected through the long form of the International Physical Activity Questionnaire (IPAQ-LF). Generalized estimating equations were used to examine adjusted associations between environmental measures and transport and overall walking.

Results. Participants ( $n=887$ ) averaged 47 years of age $(S D=13.65)$ and reported $67 \mathrm{~min} /$ week $(S D=121.21)$ of transport walking and $159 \mathrm{~min} /$ week $(\mathrm{SD}=187.85)$ of non-occupational walking. Perceived car parking difficulty was positively related to higher levels of transport walking (OR 1.41, 95\%CI: $1.18,1.69$ ) and overall walking (OR 1.18, 95\%CI: 1.02, 1.37). Self-reported ease of walking to a transit stop was negatively associated with transport walking (OR $0.86,95 \% \mathrm{CI}: 0.76,0.97)$, but this relationship was moderated by perceived access to destinations. Walking to transit also was related to non-occupational walking (OR 0.85, 95\%CI: 0.73, 0.99).

Conclusions. Parking difficulty and perceived ease of access to transit are modifiable neighborhood characteristics associated with self-reported walking.

(C) 2008 Elsevier Inc. All rights reserved

\section{Introduction}

Previous studies have examined correlations between physical activity and neighborhood attributes, such as residential density, availability of destinations within close proximity of residential areas, and the presence of parks (Gebel et al., 2007; Owen et al., 2004; McCormack et al., 2004, 2008; Humpel et al., 2002; Pendola and Gen, 2007; Frank et al., 2004; Cerin et al., 2007; Hoehner et al., 2005). However, changing these neighborhood attributes often requires complex stakeholder interactions and can take considerable time. To increase physical activity, short-, medium- and long-term strategies are necessary (Giles-Corti, 2006). Environmental attributes that are more readily modifiable in the short term are candidates for actionable community-level interventions that can produce small wins, spur community interest, mobilize advocacy groups to support policy

\footnotetext{
* Corresponding author. Department of City and Regional Planning, University of North Carolina, Chapel Hill, CB 3140, Room 319, Chapel Hill, NC 27599-3140, USA. Fax: +1 9199625206 .

E-mail address: danrod@unc.edu (D.A. Rodríguez).
}

change, and complement other individual and community-level interventions.

The aim of this study was to examine associations between neighborhood environment attributes modifiable in the short term and walking for transport and overall walking (excluding occupational walking). Our focus is on car parking availability, access to transit, neighborhood traffic, walkways and trails, and sidewalks. Parking pricing, transit availability and traffic policies are neighborhood attributes often under direct control of local planners and decisionmakers. Although sidewalks, trails and walkways often require significant infrastructure investments, control of their implementation remains primarily with planners, whereas policies influencing land development characteristics depend on changes in the land market. This short term policy emphasis can be particularly important for residents of areas that are built up already - which contain the majority of the US population (Hobbs and Stoops, 2002).

\section{Methods}

Study areas and participants

Data was collected from two related projects assessing the relationship between residential environments and walking in two U.S. areas: the northern sector of 
Minneapolis-St Paul metropolitan area (hereinafter referred to as the 'Twin Cities') and Montgomery County, Maryland in the Washington DC metropolitan area. Although the two projects were conducted independently, they followed a similar research design, using methods of matched sampling for causal inference (Rubin, 2006) by recruiting participants living in areas hypothesized to be supportive of walking and contrasting them to other participants with similar demographic characteristics in areas believed to be less supportive of walking behaviors. The two projects also share a variety of common exposure, individual-level and outcome measures. The combination of data from the two sites provided greater statistical power and also offered the ability to compare results between sites, since prior research suggests that policy and environmental characteristics are highly context-dependent.

Perhaps the largest difference between the studies is how each operationalized a supportive walking environment in the sampling design. For the Twin Cities, 805-m contiguous square zones were superimposed on the study area, resulting in approximately 500 zones. Consistent with prevailing empirical evidence, density and street connectivity (operationalized as the area of neighborhood blocks) were identified a priori as characteristics defining the walkability of zones, where zones having the highest density and smallest block area were the most walkable and zones with the lowest density and highest block areas were the least walkable. Each zone was classified into 3 density categories ( $\leq 5$, between 5 and $9.9, \geq 10$ persons/acre) and 3 block area categories ( $\leq 5$, between 5.1 and 7.9 acres $\geq 8$ acres). Thirty six zones were sampled at random from the universe of zones representing the four extreme category combinations (high density, high block size; high density, low block size; low density, high block size; low density, low block size). Participants were recruited from these 36 zones in approximately equal proportions (see Forsyth et al., 2007 for additional details).

For Montgomery County, each of the 318 zones used by the County for community planning were characterized according to their development characteristics (density of population, employment, open space and housing), motorized activity (proximity to bus and rail, population percentage taking transit commuting to work in 2000 , and road way and bus route density), and pedestrian infrastructure (sidewalk connectivity, sidewalk coverage and population percentage walking or cycling to work in 2000). A built environment score was then used to classify each zone into one of three categories of walkability using factor and cluster analysis: high ( 30 zones), middle ( 135 zones) and low (153 zones) (Young and Rodriguez, 2005). Five zones were selected at random: two from the middle and high categories and only one from the low-walkability zone because such zones cover large land areas, thus requiring substantially greater resources for field data collection.

A total of 1008 individuals (715 is the Twin Cities and 293 in Montgomery County) enrolled in the studies between April and November 2004 and January 2005 and September 2006. Able-bodied, healthy adults residing in one of the selected zones, not traveling out of town during the week of data collection and reporting the capability to walk unassisted for $20 \mathrm{~min}$ or longer were eligible. In both sites individuals were recruited randomly through mailed postcards and direct telephone calls, and for Montgomery County, home visits also were used. For 16 zones in the Twin Cities and the Montgomery County zones non-random selection of individuals was used to augment the sample. Multivariate analyses for the Twin Cities' participants show randomly selected and volunteer subjects to be similar and therefore supplementing random recruits with volunteers did not introduce significant bias (Oakes et al., 2007).

Respondents completed a questionnaire about perceived neighborhood environments (Saelens et al., 2003), social cohesion (Sampson et al., 1997), self-efficacy (Marcus et al., 1992) and social support for physical activity (Sallis et al., 1987), and sociodemographic characteristics and physical activity patterns, all with adequate psychometric properties. After accounting for survey data completeness the final sample size reduced to 887

\section{Walking activity}

The long form (27 items) of the International Physical Activity Questionnaire (IPAQLF) was used to measure frequency, intensity, and duration of occupational, transportation, home, leisure/sport, and sitting activity over the previous 7 days. IPAQ-LF has been shown to have acceptable measurement properties (Craig et al., 2003 Hagstromer et al., 2006). From the IPAQ-LF, two outcome measures were derived: walking time for transportation and overall walking time, each classified into three groups (none, $<150 \mathrm{~min} /$ week, $>=150 \mathrm{~min} /$ week) to facilitate comparison with public health guidelines.

\section{Built environment characteristics}

The Neighborhood Environment Walkability Scale (NEWS) survey was used to elicit participants' perceptions of features in their home neighborhood environment than can be changed in a short time frame (Table 1). Neighborhoods were defined as the area within a 20-min walk or 1-mi radius from the participant's home, assuming the average walking speed of $2.72 \mathrm{mph}$ used in transportation planning (Transportation Research Board, 2000). We also included self-reported access to destinations reported in NEWS to account for the potential confounding effect of walkability. Test-retest reliability of individual items except for sidewalk availability range from 0.37 to 0.7 (Sallis, 2007).

In addition to self-reported information, secondary data provided by local and county officials was used to derive objective, participant-specific measures. Two measures of transit availability (distance to nearest bus or rail stop and the number of bus stops within each participant-specific circle) and sidewalk availability (sidewalk density around each participant's home) were used (Table 1). Population density, measured as the number of residents per hectare of land (excluding water), was used to control for confounding effects of denser environments. All objective measures were calculated using a $1 / 4 \mathrm{mi}(400 \mathrm{~m})$ aerial circle around each participant's home, except the distance to transit which relied on the same distance but measured on the road network. Methods were approved by the Institutional Review Boards of University of North Carolina and the University of Minnesota.

\section{Statistical analyses}

Marginal models fitted by generalized estimating equations (GEE) (Liang and Zeger, 1986) were used to analyze the three-level ordered categorical outcomes (e.g., no walking, $<150 \mathrm{~min} /$ week, $\geq 150 \mathrm{~min} /$ week), using a cumulative logit link function and a multinomial distribution. These models appropriately account for the clustered data structure. Robust standard errors were used to account for the correlation of individuals belonging to the same zone. Because the policy-relevant environmental attributes relate to the community level, we were primarily interested in estimating between-area effects, rather than within-area (individual-level) effects.

None of the environmental attributes had particularly high colinearity (tolerance $>0.25$ ). As a result, attributes were first examined by entering each variable separately into a series of models adjusted for participants' age, gender, income level, and race and self-reported access to destinations, neighborhood population density, and study site (Twin Cities vs. Montgomery County). Next, significant environmental variables $(\alpha=0.05)$ from the separate models were entered into a single model, adjusted for socio-demographics. Coefficients for the variables can be interpreted as the population average effect of a $1 \mathrm{U}$ change in the environmental attribute on the log odds of a onelevel increase in walking. Models stratified by site were also examined to assess the stability of the coefficients across study sites. Statistical analyses were performed using SAS (SAS Institute Inc., 2002).

Access to destinations may moderate the effect of the significant environmental variables considered. As a result, we re-estimated the models by including an interaction between access to destinations and the environmental variables of interest, although the study was not specifically powered to assess interactions.

Finally, to assess whether the proportional odds assumption was reasonable and to examine different model specifications, we dichotomized the outcomes and compared

\section{Table 1}

Short-term modifiable neighborhood attributes assessed and their measurement (Minneapolis-St Paul, MN and Montgomery County, MD, USA, 2004-2006)

\begin{tabular}{|c|c|}
\hline Domain & Survey item or GIS measure \\
\hline & Parking is difficult in local shopping areas \\
\hline Transit & $\begin{array}{l}\text { It is an easy walk to a transit stop (bus, train) from your home } \\
\text { Distance to nearest bus stop ( } 100 \mathrm{ft} \text { )* } \\
\text { Bus stop density (number per acre)* }\end{array}$ \\
\hline $\begin{array}{l}\text { Walkways and } \\
\text { crosswalks }\end{array}$ & $\begin{array}{l}\text { There are walkways in your neighborhood that connect cul-de-sacs to } \\
\text { streets, trails, or other cul-de-sacs } \\
\text { There are bicycle or pedestrian pathways or trails in or near your } \\
\text { neighborhood that are easy to get to } \\
\text { The crosswalks in your neighborhood help walkers feel safe crossing } \\
\text { busy streets }\end{array}$ \\
\hline Sidewalks & $\begin{array}{l}\text { There are sidewalks on most of the streets in your neighborhood } \\
\text { The sidewalks in your neighborhood are well maintained } \\
\text { (paved, even, and not a lot of cracks) } \\
\text { Sidewalks are separated from the road/traffic in your neighborhood by } \\
\text { parked cars } \\
\text { Sidewalk density ( } 100 \mathrm{ft} / \mathrm{ac})^{*}\end{array}$ \\
\hline Traffic & $\begin{array}{l}\text { There is so much traffic along the street you live on that it makes in } \\
\text { difficult or unpleasant to walk in your neighborhood } \\
\text { There is so much traffic along nearby streets on that it makes in } \\
\text { difficult or unpleasant to walk in your neighborhood } \\
\text { The speed of traffic on most nearby streets is usually slow ( }<=30 \mathrm{mph} \text { ) } \\
\text { When walking in your neighborhood there are a lot of exhaust fumes } \\
\text { (such as from cars, buses) }\end{array}$ \\
\hline Access & There are many places to go within easy walking distance of your home \\
\hline
\end{tabular}

All measures were self-reported and were measured using a 4-point Likert scale where 1 = strongly disagree and $4=$ strongly agree with the statement provided except for those with an asterisk.

*GIS measures were calculated as follows: distance to nearest bust stop is the network distance from each participant's home location to the nearest stop measured using ESRI's network analyst (Redlands, CA) in hundreds of feet. Density of bus stops is the number of bus stops contained within the $1 / 4$ mile $(400 \mathrm{~m}$ ) aerial circle drawn from each participant's home divided by the land area (in acres) within the circle excluding water bodies. Sidewalk density is the length of sidewalks (hundred of feet) contained within the $1 / 4$ mile aerial circle drawn from each participant's home divided by the land area within the circle excluding water bodies. 
Table 2

Descriptive statistics of socio-demographics and neighborhood short-term modifiable attributes (Minneapolis-St Paul, MN and Montgomery County, MD, USA, 2004-2006)

\begin{tabular}{|c|c|c|c|c|c|}
\hline & & \multicolumn{2}{|c|}{$\begin{array}{l}\text { Montgomery } \\
\text { County } \\
(n=274)\end{array}$} & \multicolumn{2}{|c|}{$\begin{array}{l}\text { Twin Cities } \\
(n=613)\end{array}$} \\
\hline & & Mean & SD & Mean & SD \\
\hline \multirow{4}{*}{$\begin{array}{l}\text { Socio- } \\
\text { demographics }\end{array}$} & Sex $($ male $=$ reference $=2)$ & 1.34 & 0.47 & 1.34 & 0.47 \\
\hline & Age & 49.86 & 14.09 & 46.42 & 13.32 \\
\hline & Income level ${ }^{\dagger}$ & 3.15 & 0.95 & 2.22 & 0.93 \\
\hline & $\begin{array}{l}\text { Race (white; } \\
\text { nonwhite = reference }=2 \text { ) }\end{array}$ & 1.18 & 0.39 & 1.15 & 0.35 \\
\hline Parking & Parking is difficult & 2.07 & 1.03 & 1.60 & 0.79 \\
\hline \multirow[t]{3}{*}{ Transit } & Easy to walk to transit stop & 3.66 & 0.70 & 3.59 & 0.83 \\
\hline & $\begin{array}{l}\text { Distance to nearest transit stop } \\
(100 \mathrm{ft})\end{array}$ & 12.34 & 10.41 & 10.72 & 10.12 \\
\hline & Bus stop density (number per acre) & 0.28 & 0.26 & 0.18 & 0.08 \\
\hline \multirow[t]{3}{*}{$\begin{array}{l}\text { Walkways and } \\
\text { crosswalks }\end{array}$} & $\begin{array}{l}\text { Walkways connecting cul-de-sacs, } \\
\text { trails, and streets }\end{array}$ & 2.78 & 1.14 & 1.99 & 1.14 \\
\hline & Bicycle/pedestrian trails & 3.13 & 1.02 & 3.09 & 1.09 \\
\hline & $\begin{array}{l}\text { The crosswalks in your } \\
\text { neighborhood help walkers feel } \\
\text { safe crossing busy streets }\end{array}$ & 3.12 & 0.76 & 2.39 & 1.00 \\
\hline \multirow[t]{4}{*}{ Sidewalks } & Sidewalks on most streets & 3.07 & 1.06 & 2.85 & 1.18 \\
\hline & Sidewalks are well maintained & 3.37 & 0.88 & 2.86 & 1.11 \\
\hline & $\begin{array}{l}\text { Sidewalks separated from road/ } \\
\text { traffic by parked cars }\end{array}$ & 2.71 & 1.13 & 2.56 & 1.16 \\
\hline & Sidewalk density (100 ft/ac) & 120.44 & 42.43 & 144.03 & 132.74 \\
\hline \multirow[t]{4}{*}{ Traffic } & Heavy traffic along own street & 1.52 & 0.77 & 1.81 & 0.91 \\
\hline & Heavy traffic along nearby streets & 2.15 & 1.01 & 2.11 & 0.93 \\
\hline & $\begin{array}{l}\text { Slow speed of traffic along own } \\
\text { street }\end{array}$ & 2.58 & 1.06 & 2.66 & 0.94 \\
\hline & $\begin{array}{l}\text { High exhaust fumes from cars and } \\
\text { buses }\end{array}$ & 2.00 & 0.94 & 1.99 & 0.93 \\
\hline $\begin{array}{l}\text { Access to } \\
\text { destinations }\end{array}$ & $\begin{array}{l}\text { Destinations within easy walking } \\
\text { distance }\end{array}$ & 2.91 & 1.10 & 2.87 & 0.98 \\
\hline \multirow[t]{2}{*}{ Outcomes } & Walking for transport (min/week) & 72.02 & 116.70 & 65.52 & 123.22 \\
\hline & Total walking (min/week) & 168.53 & 183.55 & 154.13 & 189.72 \\
\hline
\end{tabular}

For detailed description of environmental measures, see Table 1.

†Income levels were $\leq \$ 30,000$; between $\$ 30,000$ and $\$ 60,000$ (inclusive); between $\$ 60,000$ and $\$ 100,000$; and 4$) \geq \$ 100,000$.

results from GEE models using a logit link function and a binomial distribution (Bender and Grouven, 1998).

\section{Results}

Table 2 shows descriptive statistics for socio-demographic characteristics and urban form characteristics by site. Participants engaged in an average of $67 \mathrm{~min} /$ week of walking for transport and $159 \mathrm{~min} /$ week of overall walking, with Montgomery County participants reporting 9.3\% more transport walking and 3.5\% lower overall walking than Twin Cities participants.

The adjusted results of estimating a separate model for each environmental attribute and outcome are shown in Table 3. Results suggested that higher perceived parking difficulty in local shopping areas is positively related to more transport walking (OR $1.41,95 \% \mathrm{CI}$ : $1.18,1.69$ ) and overall walking (OR 1.18, 95\%CI: 1.02, 1.37). Reporting higher access to a transit stop was negatively related to transport walking (OR 0.86, 95\% CI: 0.76, 0.97) and to non-occupational walking (OR 0.85, 95\%CI: 0.73, 0.99). Population density and access to destinations showed consistent, positive associations with walking.

To mitigate concerns about significant results due to chance and to examine the variables' independent effects, all variables were examined jointly in a single model, with only significant variables retained (Table 4). Results confirmed the association between parking difficulty and transport walking (OR 1.40, 95\% CI: 1.17, 1.67) and the association between parking difficulty and overall walking (OR 1.17, $95 \%$ CI: $1.02,1.35)$. Self-reported transit access also remained associated with transport walking (OR $0.87,95 \% \mathrm{CI}$ : $0.78,0.98$ ) and with overall walking (OR 0.86, 95\%CI: 0.74, 0.99). Additionally, population density and access to destinations remained significant $\left(\mathrm{OR}_{\text {density }} 1.49,95 \% \mathrm{CI}: 1.22,1.82 ; \mathrm{OR}_{\text {access to destinations }} 1.23,95 \% \mathrm{CI}: 1.09\right.$, 1.37) for transport walking.

Other results (not shown) included models stratified by site and models testing the moderating effects of access to destinations on selfreported access to transit and on parking difficulty. For transport walking, parking difficulty remained significant in models estimated separately for the Twin Cities, but did not remain significant in Montgomery County $\left(\mathrm{OR}_{\text {Montgomery County }} 1.42,95 \% \mathrm{CI}\right.$ : 0.94, 2.14; $\mathrm{OR}_{\text {Twin Cities }} 1.38,95 \% \mathrm{CI}$ : 1.18,1.63), likely the result of low power (only 5 neighborhood clusters) in Montgomery County. Also for transport walking, self-reported access to transit remained significant for Mongtomery County (OR 0.77, 95\%CI: 0.64, 0.92) but was not significant in the Twin Cities. Self-reported sidewalk availability was positively related to transport walking in the Twin Cities $\left(\mathrm{OR}_{\mathrm{Twin}}\right.$ Cities 1.19, 95\%Cl: 1.06, 1.34). For overall walking, the only significant environmental measure was self-reported sidewalks for the Twin Cities (OR 1.14, 95\%CI: 1.01, 1.30).

The results of moderation tests for the transport walking outcome showed that transit access appears to be moderated by perceived access to destinations, but parking difficulty does not appear to be moderated by the same variable. The interaction effect of high transit access in the presence of high access to destinations is related to higher walking levels for transport (OR 1.23, 95\%CI: 1.04, 1.45). No significant interactions between these variables were observed for overall walking.

\section{Discussion}

Neighborhood attributes modifiable in the short term and their relationship to two types of walking activity were the focus of this

\section{Table 3}

Results of GEE models (one per exposure) explaining transport walking and nonoccupational walking, adjusted $(n=887)^{\mathrm{a}, \mathrm{b}}$ (Minneapolis-St Paul, MN and Montgomery County, MD, USA, 2004-2006)

\begin{tabular}{|c|c|c|c|}
\hline & & $\begin{array}{l}\text { Transport } \\
\text { walking }^{\mathrm{c}}\end{array}$ & $\begin{array}{l}\text { Non-occupationa } \\
\text { walking }^{\mathrm{c}}\end{array}$ \\
\hline & & OR $(95 \% \mathrm{CI})$ & OR $(95 \% \mathrm{CI})$ \\
\hline Parking & Parking is difficult & $1.41(1.18,1.69)$ & $1.18(1.02,1.37)$ \\
\hline \multirow[t]{3}{*}{ Transit } & Easy to walk to transit stop & $0.86(0.76,0.97)$ & $0.85(0.73,0.99)$ \\
\hline & Distance to nearest transit stop & $1.00(0.99,1.00)$ & $1.00(0.99,1.00)$ \\
\hline & Bus stop density & $0.82(0.31,2.21)$ & $0.79(0.25,2.46)$ \\
\hline \multirow[t]{3}{*}{$\begin{array}{l}\text { Walkways and } \\
\text { crosswalks }\end{array}$} & $\begin{array}{l}\text { Walkways connecting cul-de- } \\
\text { sacs, trails, and streets }\end{array}$ & $1.01(0.92,1.11)$ & $1.06(0.93,1.20)$ \\
\hline & Bicycle/pedestrian trails & $1.04(0.93,1.16)$ & $1.05(0.91,1.21)$ \\
\hline & $\begin{array}{l}\text { The crosswalks in your } \\
\text { neighborhood help walkers feel } \\
\text { safe crossing busy streets }\end{array}$ & $0.99(0.84,1.18)$ & $1.11(0.93,1.33)$ \\
\hline \multirow[t]{4}{*}{ Sidewalks } & Sidewalks on most streets & $1.09(0.97,1.22)$ & $1.04(0.93,1.17)$ \\
\hline & Sidewalks are well maintained & $0.94(0.84,1.06)$ & $1.05(0.94,1.18)$ \\
\hline & $\begin{array}{l}\text { Sidewalks separated from road/ } \\
\text { traffic by parked cars }\end{array}$ & $0.99(0.87,1.14)$ & $1.03(0.92,1.16)$ \\
\hline & Sidewalk density & $1.01(0.99,1.03)$ & $0.99(0.98,1.02)$ \\
\hline \multirow[t]{4}{*}{ Traffic } & Heavy traffic along own street & $1.10(0.97,1.26)$ & $0.96(0.85,1.09)$ \\
\hline & $\begin{array}{l}\text { Heavy traffic along nearby } \\
\text { streets }\end{array}$ & $1.11(0.97,1.25)$ & $1.01(0.89,1.15)$ \\
\hline & $\begin{array}{l}\text { Slow speed of traffic along own } \\
\text { street }\end{array}$ & $0.96(0.83,1.06)$ & $0.91(0.81,1.02)$ \\
\hline & $\begin{array}{l}\text { High exhaust fumes from cars } \\
\text { and buses }\end{array}$ & $1.02(0.90,1.16)$ & $0.97(0.88,1.07)$ \\
\hline
\end{tabular}

For detailed description of environmental measures, see Table 1. Bolded font denotes statistical significance at a $95 \%$ level of confidence or higher.

a Robust standard errors clustered by zone of residence are used to calculate confidence intervals and determine statistical significance.

b Adjusted for participant age, income level, sex (male = reference), race (nonwhite = reference), population density, self-reported access to destinations, and study site (Montgomery County $=$ reference).

c Walking time was collapsed into three categories: none (reference), $<150 \mathrm{~min} /$ week, and $\geq 150 \mathrm{~min} /$ week, with the latter corresponding to the time required for meeting PA standards from moderate activity. 
Table 4

Results of GEE models with significant exposures explaining walking for transport and nonoccupational walking, adjusted $(n=887)^{\mathrm{a}, \mathrm{b}, \mathrm{c}}$ (Minneapolis-St Paul, MN and Montgomery County, MD, USA, 2004-2006)

\begin{tabular}{|c|c|c|c|}
\hline & & \multirow{2}{*}{$\begin{array}{l}\text { Transport } \\
\text { walking } \\
\text { OR } \\
(95 \% \mathrm{CI})\end{array}$} & \multirow{2}{*}{$\begin{array}{l}\text { Non-occupational } \\
\text { walking } \\
\text { OR } \\
(95 \% \mathrm{CI})\end{array}$} \\
\hline & & & \\
\hline Parking & Parking is difficult & $\begin{array}{l}1.40 \\
(1.17,1.67)\end{array}$ & $1.17(1.02,1.35)$ \\
\hline \multirow[t]{3}{*}{ Transit } & Easy to walk to transit stop & $\begin{array}{l}0.87 \\
(0.78,0.98)\end{array}$ & $0.86(0.74,0.99)$ \\
\hline & Distance to nearest transit stop & - & \\
\hline & Bus stop density & - & \\
\hline \multirow[t]{3}{*}{$\begin{array}{l}\text { Walkways and } \\
\text { crosswalks }\end{array}$} & $\begin{array}{l}\text { Walkways connecting cul-de-sacs, } \\
\text { trails, and streets }\end{array}$ & - & \\
\hline & Bicycle/pedestrian trails & - & \\
\hline & $\begin{array}{l}\text { The crosswalks in your } \\
\text { neighborhood help walkers feel safe } \\
\text { crossing busy streets }\end{array}$ & - & \\
\hline \multirow[t]{3}{*}{ Sidewalks } & Sidewalks on most streets & - & \\
\hline & Sidewalks are well maintained & - & \\
\hline & $\begin{array}{l}\text { Sidewalks separated from road/ } \\
\text { traffic by parked cars }\end{array}$ & - & \\
\hline \multirow[t]{4}{*}{ Traffic } & Heavy traffic along own street & - & \\
\hline & Heavy traffic along nearby streets & - & \\
\hline & $\begin{array}{l}\text { Slow speed of traffic along own } \\
\text { street }\end{array}$ & - & \\
\hline & $\begin{array}{l}\text { High exhaust fumes from cars and } \\
\text { buses }\end{array}$ & - & \\
\hline
\end{tabular}

For detailed description of environmental measures, see Table 1. Bolded font denotes statistical significance at a $95 \%$ level of confidence or higher.

a Robust standard errors clustered by zone of residence are used to calculate confidence intervals and determine statistical significance.

b Adjusted for participant age, income level, sex (male = reference), race (nonwhite = reference), population density, self-reported access to destinations, and study site (Montgomery County $=$ reference).

c Walking time was collapsed into three categories: none (reference), $<150 \mathrm{~min} /$ week, and $\geq 150 \mathrm{~min} /$ week, with the latter corresponding to the time required for meeting PA standards from moderate activity.

study. Perceived car parking difficulty, likely due to the limited availability of parking spaces or its cost, was consistently related to higher levels of walking. By contrast, a national study of 10 metropolitan areas in the U.S. using travel diaries found that the number of residents per foot of parkable street length was unrelated to utilitarian walking (Boer et al., 2007). The more direct measure used in this study appears more suited for interpretation and policy analysis.

The importance of parking as a policy lever is increasingly recognized among planning researchers (Shoup, 2005), yet political support is weak. In practice, parking policies are frequently determined based on arbitrary standards and limited evidence (Marsden, 2006). Free car parking is viewed as invitation to drive, while rationing parking through supply controls or through higher pricing has been related to more cycling, fewer car miles, and fewer single-occupancy vehicle trips (Cervero and Kockelman, 1997; Pucher and Buehler, 2006). Overcoming resistance to parking changes requires a concerted effort to address misperceptions and demonstrate the cost and community impacts of prevailing parking policies. Perhaps when implemented in the context of broader multi-level individual and community-level interventions, support for parking changes may increase. For example, as evidence continues to support enhancing availability and diversity of destinations within neighborhoods to increase walking for transport (Hoehner et al., 2005; McCormack et al., 2008), managing the availability of parking is likely to be a successful complementary strategy. An opportunity to manage parking emerges as destinations become popular. With scarce funds, limiting car parking availability through space or pricing constraints may be an important intervention strategy to promote walking.

Initial results for perceived access to transit service suggested an unexpected relationship, with better self-reported access related to lower levels of walking. This contradicts evidence suggesting that perceived and objective distance to transit is related to higher levels of physical activity (Hoehner et al., 2005; McCormack et al., 2008). Transit users engage in more walking than non-transit users, and therefore improved access to transit may help promote physical activity (Wener and Evans, 2007; Besser and Dannenberg, 2005). However, the moderating effect of access to destinations observed in our study provided a more complex picture regarding the importance of transit proximity. In the presence of high access to destinations, high access to transit was related to more walking relative to areas with low access to transit or low access to destinations, all else held equal. Others have identified this complex relationship and suggested that increased physical activity may be stimulated if walking to transit occurs in the context of other neighborhood destinations like stores (Brown and Werner, 2007). As with parking, complementary interventions to create neighborhoods environments supportive of everyday walking may be an effective strategy to increase physical activity. With limited funds for expanding transit, service improvements in local shopping areas appear to be most promising.

The reported presence of walkways, trails, and crosswalks were not significant in any of the pooled models. One study of a Massachusetts suburb reported similar results for self-reported presence of crosswalks (Troped et al., 2003), but another study in Jackson, Mississippi and Forsyth County, North Carolina found significant relationships between crosswalks and physical activity for recreational and utilitarian purposes (McGinn et al., 2007). Jackson and Forsyth County may be showing crosswalks' significance because of the autoorientation of those areas relative to the Massachusetts suburb and our study areas. When connectivity is low, pedestrians and traffic converge at few intersections, and therefore crosswalks may be more relevant in those contexts. Another potential explanation is that our sample is predominantly white, whereas there is evidence that nonwhite populations may respond differently to environmental supports for transportation physical activity (Aytur et al., 2007).

Our study has several strengths and limitations. Although not intended as representative of the population due to the sampling strategy, the careful research design allows a richer examination of relationships between the environment and activity. However, the caveats of cross-sectional designs still apply, including the possibility of self-sorting in the residential land market. Our emphasis on policyrelevant, modifiable environmental attributes in the short term appears unique to the study. Combining the data from two studies is both a strength and limitation. Although this increased statistical power allowed us to compare models between sites, it also introduced different sample sizes and different methodologies for selecting study areas, which may increase heterogeneity with respect to omitted variables. Other limitations include the use of aerial distances for measuring environmental attributes, the fact that walking was selfreported and recruitment was not fully random, although data quality and completeness mitigate the limited randomness. Although we followed a traditional model selection procedure (bivariate followed by multivariate), this is not without limitations (Henderson and Velleman, 1981). Additionally, our model assumes that odds are proportional as the walking category increases. We tested other specifications within GEE that do not make this assumption and found our results to be generally consistent.

\section{Conclusions}

This study finds that perceived car parking difficulty is related to higher levels of transport walking and overall walking. By contrast, other environmental attributes such as sidewalks, walkways and trails, and neighborhood traffic were unrelated to either type of walking in pooled analyses, although sidewalks were significant in models for the Twin Cities. Further research should test these relationships in other contexts and with diverse populations. 
Policies influencing parking appear to be among the most promising strategies to increase walking. The moderating effect of perceived access to destinations further suggests that efforts to expand transit access should concentrate in areas with proximate destinations, where combinations of walking, cycling and transit could substitute for driving. The results for parking resonate well with planners who have increasing awareness of the effect of parking supply on travel patterns. Collaborative efforts between planners and public health professionals to address policies targeting readily modifiable attributes such as parking may prove to be effective interventions to increase walking.

\section{Acknowledgments}

Preparation of this article was supported by a grant from the Robert Wood Johnson Foundation Active Living Research program.

\section{References}

Aytur, S.A., Rodriguez, D.A., Evenson, K.R., Catellier, D.J., Rosamond, W.D., 2007. Promoting active community environments through land use and transportation planning. Am. J. Health Promot. 21, 397-407.

Bender, R., Grouven, U., 1998. Using binary logistic regression models for ordinal data with non-proportional odds. J. Clin. Epidemiol. 51, 809-816.

Besser, L.M., Dannenberg, A.L., 2005. Walking to public transit: steps to help meet physical activity recommendations. Am. J. Prev. Med. 29, 273-280.

Boer, R., Zheng, Y., Overton, A., Ridgeway, G.K., Cohen, D.A., 2007. Neighborhood design and walking trips in ten U.S. metropolitan areas. Am. J. Prev. Med. 32, 298-304.

Brown, B.B., Werner, C.M., 2007. A new rail stop - Tracking moderate physical activity bouts and ridership. Am. J. Prev. Med. 33, 306-309.

Cerin, E., Leslie, E., du Toit, L., Owen, N., Frank, L.D., 2007. Destinations that matter: associations with walking for transport. Health Place 13, 713-724.

Cervero, R., Kockelman, K., 1997. Travel demand and the 3Ds: density, diversity and design. Transp. Res. D 2, 199-219.

Craig, C.L., Marshall, A.L., Sjostrom, M., Bauman, A.E., Booth, M.L., Ainsworth, B.E., Pratt M., Ekelund, U., Yngve, A., Sallis, J.F., Oja, P., 2003. International physical activity questionnaire: 12-country reliability and validity. Med. Sci. Sports Exerc. 35, 1381-1395.

Forsyth, A., Oakes, M., Schmitz, K., Hearst, A., 2007. Does residential density increase walking and other physical activity? Urban Stud. 44, 679-697.

Frank, L.D., Andresen, M.A., Schmid, T.L., 2004. Obesity relationships with community design, physical activity, and time spent in cars. Am. J. Prev. Med. 27, 87-96.

Gebel, K., Bauman, A.E., Petticrew, M., 2007. The physical environment and physical activity a critical appraisal of review articles. Am. J. Prev. Med. 32, 361-369.

Giles-Corti, B., 2006. People or places: what should be the target? J. Sci. Med. Sport 9, 357-366.

Hagstromer, M., Oja, P., Sjostrom, M., 2006. The International Physical Activity Questionnaire (IPAQ): a study of concurrent and construct validity. Public Health Nutr. 9, 755-762.

Henderson, H., Velleman, P., 1981. Building multiple regression models interactively. Biometrics 37, 391-411.

Hobbs, F., Stoops, N., 2002. Demographic Trends in the 20th Century, Census 2000 Special Reports, Report No. CENSR-4.
Hoehner, C.M., Ramirez, L.K.B., Elliott, M.B., Handy, S.L., Brownson, R.C., 2005. Perceived and objective environmental measures and physical activity among urban adults. Am. J. Prev. Med. 28, 105-116.

Humpel, N., Owen, N., Leslie, E., 2002. Environmental factors associated with adults participation in physical activity. Am. J. Prev. Med. 22, 188-199.

Liang, K.Y., Zeger, S.L., 1986. Longitudinal regression analysis using generalized linear models. Biometrika 73, 13-22.

Marcus, B.H., Rossi, J.S., Selby, V.C., Niaura, R.S., Abrams, D.B., 1992. The stages and processes of exercise adoption and maintenance in a worksite sample. Health Psychol. 11, 386-395.

Marsden, G., 2006. The evidence base for parking policies - A review. Transp. Policy 13 447-457.

McCormack, G., Giles-Corti, B., Lange, A., Smith, T., Martin, K., Pikora, T., 2004. An update of recent evidence of the relationship between objective and self-report measures of the physical environment and physical activity behaviours. J. Sci. Med. Sport 7, 81-92.

McCormack, G.R., Giles-Corti, B., Bulsara, M., 2008. The relationship between destination proximity, destination mix and physical activity behaviors. Prev. Med. 46, 33-40.

McGinn, A.P., Evenson, K.R., Herring, A.H., Huston, S.L., Rodriguez, D.A., 2007. Exploring associations between physical activity and perceived and objective measures of the built environment. J. Urban Health 84, 162-184.

Oakes, M., Forsyth, A., Hearst, M.O., Schmitz, K., 2007. Recruiting subjects for neighborhood effects research: Strategies and outcomes of the Twin Cities Walking Study, unpublished mimeo, 23.

Owen, N., Humpel, N., Leslie, E., Bauman, A., Sallis, J.F., 2004. Understanding environmental influences on walking: review and research agenda. Am. J. Prev. Med. 27, 67-76.

Pendola, R., Gen, S., 2007. BMI, auto use, and the urban environment in San Francisco. Health Place 13, 551-556.

Pucher, J., Buehler, R., 2006. Why Canadians cycle more than Americans: a comparative analysis of bicycling trends and policies. Transp. Policy 13, 265-279.

Rubin, D.B., 2006. Matched sampling for causal effects. Cambridge University Press, Cambridge.

Saelens, B.E., Sallis, J.F., Black, J.B., Chen, D., 2003. Neighborhood-based differences in physical activity: an environment scale evaluation. Am. J. Public Health 93, 1552-1558.

Sallis, J., 2007. http://www.drjamessallis.sdsu.edu/NEWS_individual_item_reliability. pdf, Accessed May 17.

Sallis, J.F., Grossman, R.M., Pinski, R.B., Patterson, T.L., Nader, P.R., 1987. The development of scales to measure social support for diet and exercise behaviors. Prev. Med. 16, 825-836.

Sampson, R.J., Raudenbush, S.W., Earls, F., 1997. Neighborhoods and violent crime: multilevel study of collective efficacy. Science 277, 918-924.

SAS Institute Inc., 2002. SAS v8.2, Cary, NC.

Shoup, D.C., 2005. The High Cost of Free Parking. Planners Press, American Planning Association, Chicago.

Transportation Research Board, 2000. Highway Capacity Manual. National Academy Press, Washington, D.C.

Troped, P.J., Saunders, R.P., Pate, R.R., Reininger, B., Addy, C.L., 2003. Correlates of recreational and transportation physical activity among adults in a. N. Engl. Community Prev. Med. 37, 304-310.

Wener, R.E., Evans, G.W., 2007. A morning stroll - levels of physical activity in car and mass transit commuting. Environ. Behav. 39, 62-74.

Young, H., Rodriguez, D.A., 2005. Using Census Data to Examine the Pedestrian Friendliness of the Built Environment, Census Data for Transportation Planning: Preparing for the Future. Transportation Research Board, Irvine, CA. 